\title{
El papel de las pruebas diagnósticas en el manejo de la pandemia COVID-19: un enfoque desde el laboratorio clínico
}

\author{
The role of diagnostic tests in the management of the COVID-19 pandemic: \\ an approach from the clinical laboratory \\ Carmen J. Mazariegos-Herrera ${ }^{1}$,Carmen M. Ozaeta-Gordillo², Rebeca A. Méndez-Veras ${ }^{3}$, \\ César R. Conde-Pereira ${ }^{2 *}$
}

\begin{abstract}
${ }^{1}$ Unidad Central de Referencia para la Vigilancia Epidemiológica, Laboratorio Nacional de Salud, ${ }^{2}$ Departamento de Laboratorio Clínico, Hospital General San Juan de Dios, Ministerio de Salud Pública y Asistencia Social, ${ }^{3}$ Facultad de Ciencias Químicas y Biológicas, Universidad Mariano Gálvez, Guatemala

*Autor al que se dirige la correspondencia: cesarcondepereira@gmail.com
\end{abstract}

Recibido: 10 de agosto 2020 / Revisión: 19 de octubre 2020 / Aceptado: 05 de noviembre 2020

Resumen

\begin{abstract}
A finales del 2019 una crisis sanitaria se desató a nivel mundial debido a la propagación del nuevo virus SARSCoV-2 causante de la enfermedad COVID-19. En pocos meses el virus llegó a más de 120 países, causando cerca de 19.5 millones de casos y 725,000 muertes alrededor del mundo. La sintomatología de la enfermedad incluye fiebre, tos, cefalea, dolor de garganta, dificultad respiratoria, fatiga y mialgia. El espectro de la enfermedad puede ir desde los pacientes asintomáticos o leves (la gran mayoría de los casos) hasta aquellos que evolucionan a condiciones que amenazan la vida como el síndrome de dificultad respiratoria aguda, neumonía severa o fallo multiorgánico, principalmente en personas mayores y con comorbilidades. En Guatemala la letalidad es del 3.9\%. El diagnóstico de laboratorio clínico juega un papel importante en el control de la pandemia. El diagnóstico se basa en la detección del virus en hisopados nasofaríngeos a través de técnicas moleculares de amplificación de ácidos nucleicos. Otras técnicas de laboratorio resultan importantes para conocer la dinámica de la enfermedad, entre estas se incluyen pruebas para detectar antígeno del virus en secreciones respiratorias y pruebas serológicas para detectar y medir los anticuerpos generados contra el virus.
\end{abstract}

Palabras claves: SARS-CoV-2, COVID-19, RT-PCR, RT-LAMP, antígeno, anticuerpos

\begin{abstract}
A the end of 2019, a health crisis broke out worldwide due to the spread of the new SARS-CoV-2 virus that A causes the COVID-19 disease. In just a few months the virus reached more than 120 countries, causing about 19.5 million cases and 725,000 deaths around the world. Symptoms of the disease include fever, cough, headache, sore throat, shortness of breath, fatigue, and myalgia. The spectrum of the disease can range from asymptomatic or mild patients (the vast majority of cases) to those who evolve to life-threatening conditions such as acute respiratory distress syndrome, severe pneumonia or multiple organ failure, mainly in older people and people with comorbidities. In Guatemala, the fatality rate is 3.9\%. Clinical laboratory diagnosis plays an important role in controlling the pandemic. The diagnosis is based on the detection of the virus in nasopharyngeal swabs through molecular nucleic acid amplification techniques. Other laboratory techniques are important to understand the dynamics of the disease and include tests to detect virus antigen in respiratory secretions and serological tests to detect and measure antibodies generated against the virus.
\end{abstract}

Keywords: SARS-CoV-2, COVID-19, RT-PCR, RT-LAMP, antigen, antibodies 


\section{Introducción}

Los coronavirus son uno de los principales grupos de virus que afectan la salud pública mundial. Cuatro coronavirus son conocidos por ser agentes etiológicos de resfriados comunes y enfermedad respiratoria leve. Estos son los coronavirus HKU1, NL63, 229E y OC43. En las últimas dos décadas ha habido dos eventos relacionados a beta coronavirus de origen animal que han causado enfermedades severas en seres humanos. La primera ocurrió en 2002-2003 donde un nuevo coronavirus proveniente de los murciélagos causó un brote de neumonía denominado síndrome respiratorio agudo grave (SARS, por sus siglas en inglés) infectando a 8,422 personas en China y Hong Kong, causando 916 muertes antes de ser contenido. Una década después en el 2012, otro nuevo coronavirus identificado como MERS-CoV produjo el síndrome respiratorio agudo de Oriente Medio (MERS, por sus siglas en inglés) afectando a 2,494 personas y matando a 858 (Singhal, 2020).

En diciembre de 2019 una neumonía de origen desconocido fue descubierta en la ciudad de Wuhan, provincia de Hubei al occidente de China. Inicialmente fue identificado como un brote asociado a un mercado de mariscos donde también se vendían otros tipos de animales exóticos. Posteriormente se identificó a través de cultivos virales y análisis molecular que el agente causante de la neumonía era un nuevo coronavirus, el cual fue denominado originalmente como 2019-nCov. El Comité Internacional de Taxonomía de Virus lo renombró como SARS-CoV-2 y la Organización Mundial de la Salud (OMS) llamó COVID-19 a la enfermedad que causa. Este coronavirus es el séptimo miembro de la familia Coronaviridae que infecta a seres humanos (Sun et al., 2020).

Esta revisión tiene como objetivo resumir los aspectos generales de la pandemia del COVID-19, su agente causal el SARS-CoV-2 y las herramientas de laboratorio clínico disponibles para su diagnóstico, monitoreo y control. Para ello se revisaron las bases de datos PubMed y Google Scholar, detectándose 51 artículos que fueron analizados y cuyos principales hallazgos fueron incluidos en esta revisión.

\section{Contenido}

\section{Epidemiología}

En marzo de 2020 la OMS declara el COVID-19 como una pandemia. Para la tercera semana de julio de 2020, según el Centro de Recursos para el Coronavirus de la Universidad Johns Hopkins y el Tablero COVID-19 del Centro para las Ciencias en Sistemas e Ingeniería de la misma universidad, había alrededor del mundo cerca de 14,457,916 de casos confirmados de COVID-19 y 605,205 muertes en el mundo debido a esta enfermedad (Tablero COVID-19; Universidad John Hopkins, 2020). Para el mismo período de tiempo, en Guatemala se reportaron 38,677 casos confirmados por laboratorio y 1,485 casos fallecidos para una tasa de mortalidad local de 8.4 fallecidos por cada 100,000 habitantes (Ministerio de Salud Pública y Asistencia Social, 2020; según tablero COVID-19).

Cuando una nueva enfermedad infecciosa emerge, es sumamente importante contar con una adecuada definición de caso para realizar el diagnóstico clínico y para llevar a cabo la vigilancia epidemiológica en el sistema de salud pública. El rastreo de casos en el tiempo es importante para establecer la velocidad de la diseminación de la enfermedad y la efectividad de las intervenciones (Tsang et al., 2020). El laboratorio clínico juega un rol importante en la epidemiología del COVID-19 puesto que en la actualidad la definición de caso por lo general incluye pruebas diagnósticas realizadas en el laboratorio tanto para el diagnóstico clínico como para el rastreo de los casos (Tabla 1).

\section{Patogénesis}

Los coronavirus forman el grupo más grande de virus ARN. Están formados por una cadena única de ARN monocatenario de polaridad positiva. Causan enfermedades respiratorias, gastrointestinales y neurológicas en humanos y animales. Los más comunes son HCoV-229E, HCoV-OC43, HCoV-NL63, HCoV-HKU1, que generalmente originan los resfriados comunes en pacientes inmunocompetentes (Guo et al., 2020). El SARS-CoV-2 es un $\beta$ coronavirus responsable de la enfermedad de COVID-19.

El genoma de SARS-CoV-2 consta de un estimado de 30,000 pares de bases. Está constituido por dos marcos de lectura abierta (open reading frame-ORF-) ORF 1a y ORF 1b. Cuenta con 16 proteínas no estructurales (nsp), que están implicadas en la replicación y 
Tabla 1

Clasificación de casos de COVID-19 en Corea del Sur, Estados Unidos y Guatemala

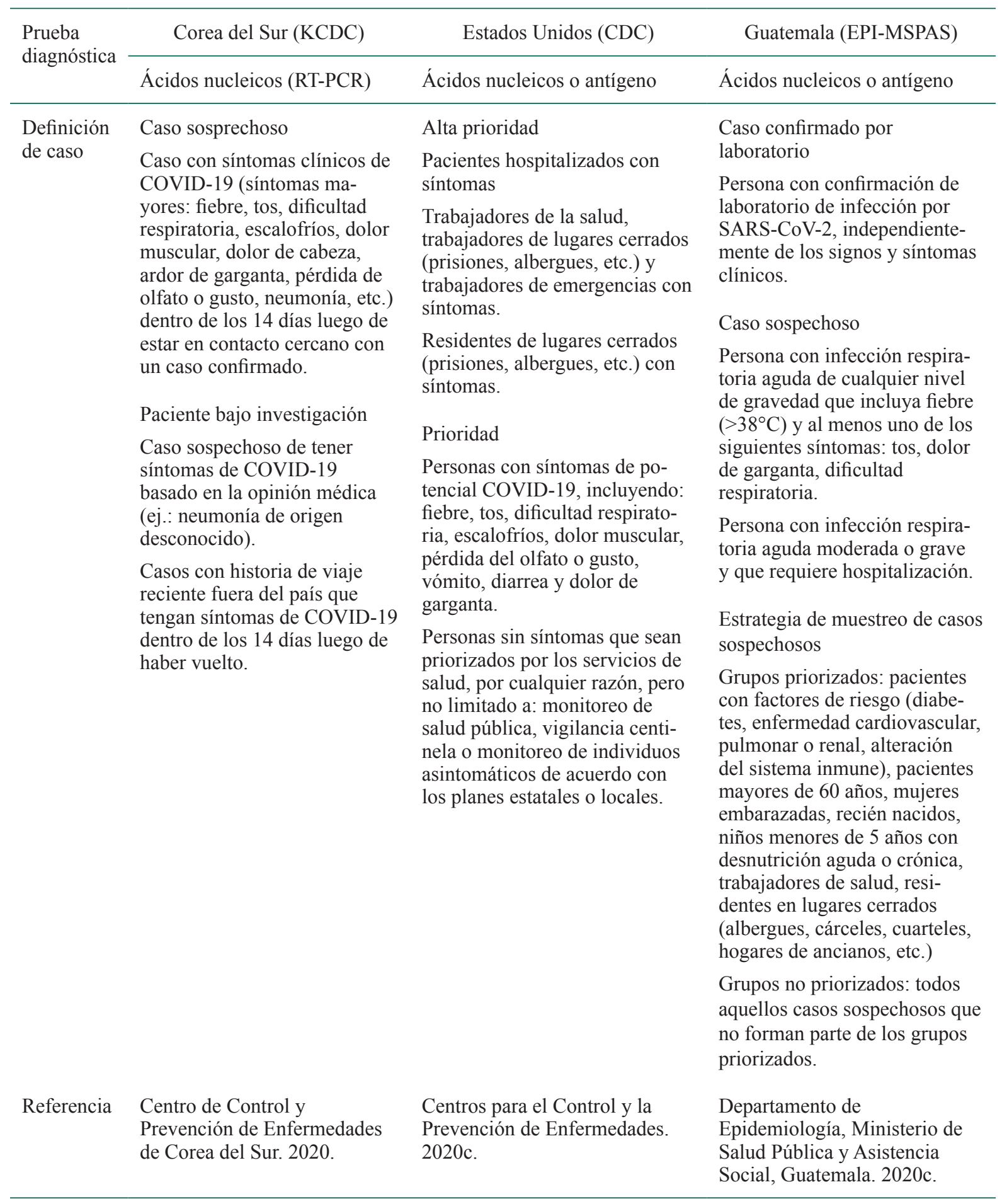

Nota. CDC: KDCA: Centro para el Control y la Prevención de Enfermedades de Corea del Sur. EPI-MSPAS: Departamento de Epidemiología, Ministerio de Salud Pública y Asistencia Social. 
transcripción viral. También contiene cuatro proteínas estructurales principales: S (spike), M (membrana), E (envoltura) y N (nucleocápside) (Figura 1) (Guo et al., 2020; Wiersinga et al., 2020). El inicio de la infección se da cuando la proteína $\mathrm{S}$ del virus se une a las células blanco a través del receptor de la enzima convertidora de angiotensina 2 (ACE2). Este receptor se encuentra expresado en el tracto respiratorio, corazón, riñón, estómago, vejiga, esófago e intestino. En la fase temprana de la infección, el SARS-CoV-2 ingresa a células tales como las epiteliales nasales y aunque el virus tiene tropismo por el tracto respiratorio superior, posteriormente a la replicación viral la infección avanza al tracto respiratorio inferior (Wiersinga et al., 2020).

La infección por SARS-CoV-2 puede ser asintomática o presentarse con una amplia gama de síntomas que van desde muy leves, hasta muy graves. Dentro de los más comunes se encuentran fiebre, tos seca, fatiga, mialgia, producción de esputo, dificultad para respirar, dolor de garganta y dolor de cabeza. Adicionalmente, pueden presentarse manifestaciones gastrointestinales como diarrea y vómitos. Algunos pacientes al final de la primera semana de síntomas pueden progresar a neumonía, falla respiratoria y muerte (Huan et al., 2020; Wiersinga et al., 2020).

Varias condiciones de salud agravan el curso de la infección. Pacientes con condiciones previas como diabetes, hipertensión arterial o enfermedad cardiovascular, obesidad o algún inmunocompromiso, pueden presentar complicaciones graves. Dentro de estas últimas se pueden mencionar: síndrome de distrés respiratorio, arritmias, shock, daño renal, daño cardíaco agudo, disfunción hepática, infección secundaria y en el peor de los casos, muerte (Guo et al., 2020). La infección tiende a progresar rápidamente en personas mayores de 65 años, lo que los hace población en riesgo.

La inmunidad para la resolución de las infecciones por coronavirus es vital, lo cual también puede conducir a una respuesta inmune fuera de control y contribuir al mal pronóstico del paciente. Al igual que en otras enfermedades respiratorias como la influenza, cuando el virus infecta a los linfocitos T puede ocurrir una profunda linfopenia. La respuesta inflamatoria viral tanto innata como adaptativa, compromete la linfopoyesis y aumenta la apoptosis de los linfocitos ( $\mathrm{Li}$ et al., 2020; Wiersinga et al., 2020). Adicionalmente a las células epiteliales, el virus infecta las células endoteliales pulmonares capilares, acentuando la respuesta inflamatoria y activando la llegada de monocitos y neutrófilos. Se presenta un infiltrado de mononucleares intersticiales inflamatorios y se desarrolla edema. La progresión es asociada con el aumento de las citoquinas inflamatorias incluyendo IL1, IL2, IL6, IL7, IL10, GCSF, IP10, MCP1, MCP1A y TNF (Guo et al., 2020; Huang et al., 2020; Manglamurti \& Hunter, 2020; Wiersinga et al., 2020).

En COVID-19 severo hay una activación fulminante de la coagulación y puede presentarse un consumo de sus factores. Los tejidos pulmonares inflamados y las células pulmonares endoteliales pueden presentar formación del microtrombos y contribuir a la alta incidencia de complicaciones trombóticas como la trombosis venosa profunda, embolismo pulmonar y complicaciones trombóticas arteriales. En pacientes infectados el desarrollo de la sepsis viral acompañada por una disfunción orgánica es causada por una respuesta inmune, irregular, tanto innata como adquirida, lo cual puede contribuir a la falla multisistémica (Wiersinga et al., 2020).

El tiempo estimado desde el aparecimiento de síntomas hasta la disnea ha sido de 5 días, a la hospitalización 7 días y el síndrome de distrés respiratorio 8 días. Las complicaciones observadas han incluido daño agudo pulmonar, síndrome de distrés respiratorio, shock y falla renal aguda. La recuperación empieza a partir de la segunda y tercera semana posterior al aparecimiento de síntomas (Huang et al., 2020; Wiersinga et al., 2020).

\section{Modo de Transmisión}

El SARS-CoV-2 es altamente contagioso y transmisible. La infección por coronavirus es contraída por entrar en contacto con pequeñas partículas o gotículas de saliva de pacientes sintomáticos. Esto puede ser a través de vía aérea o por contaminación de superficies, a las cuales la persona tiene acceso y al tocarlas, lleva el virus a su propio organismo. Las gotículas también pueden provenir de portadores asintomáticos antes del establecimiento de síntomas. Algunos estudios han demostrado altos títulos de carga viral en la cavidad nasal comparado con la garganta, sin diferencias entre pacientes sintomáticos y asintomáticos (Huang et al., 2020).

La transmisión presintomática ha sido descrita en varios estudios. El paciente presintomático puede ser infectivo, de 1 a 3 días antes del aparecimiento de síntomas. La transmisión presintomática ha sido de las mayores causales de la propagación del virus (Gao et al., 2020; Long et al., 2020). La cantidad de infecciones asintomáticas ha sido escrita desde el $40-45 \%$, pero aún no se sabe si estos pacientes representan a verdaderos asintomáticos, es decir individuos que nunca van a de- 


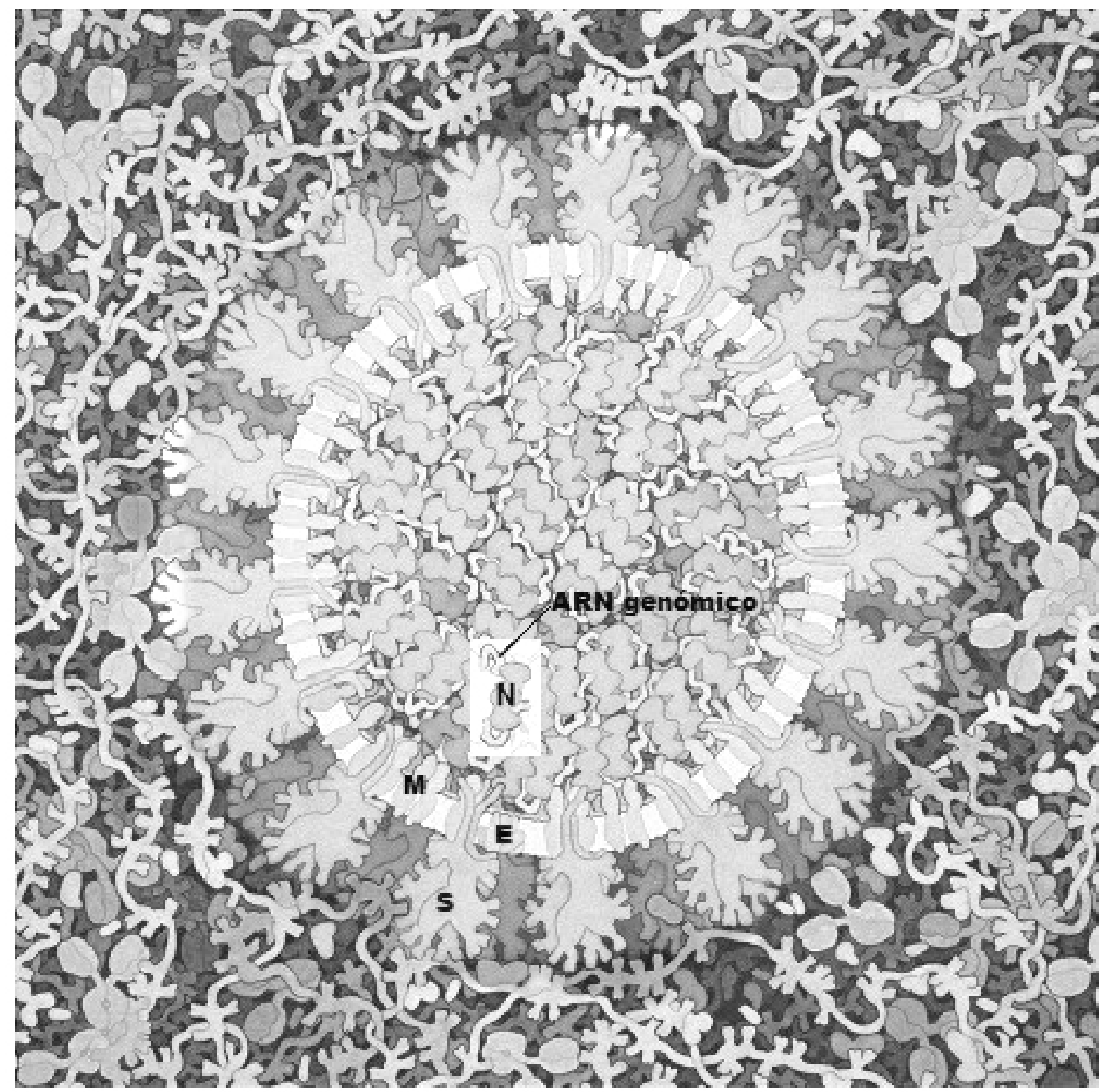

Figura 1. Coronavirus en mucosa respiratoria. Nota. De "Integrative illustration for coronavirus outreach" por D. S. Goodsell, M. Voigt, C. Zardecki, \& S. K. Burleyet, 2020, PLoS Biology, 18(8), p. 3 (https://doi.org/10.1371/journal. pbio.3000815.g001). Las proteínas de membrana y proteínas unidas a membrana se observan en magenta. El genoma viral y proteínas asociadas se observan en morado. Las proteínas virales se identifican como M: proteína de membrana, E: proteína de envoltura, N: proteína de nucleocápside y S: proteína Spike.

sarrollar síntomas, si son pacientes con síntomas muy leves o simplemente son asintomáticos al momento de la transmisión del virus, pero posteriormente desarrollan síntomas (Long et al., 2020; Oran \& Topol, 2020; Wiersinga et al., 2020). Los pacientes pueden ser infecciosos mientras presenten síntomas e incluso cuándo se estén recuperando. Algunas personas han sido catalogadas como súper propagadoras del virus ya que pueden transmitir la enfermedad sin presentar sintomatología (Gao et al., 2020). La transmisión de humano a humano puede ocurrir principalmente entre miembros de la misma familia, incluyendo familiares o amigos que mantienen contacto frecuente con pacientes con síntomas o con portadores asintomáticos.

El virus logra mantenerse viable en superficies durante días si las condiciones atmosféricas son favo- 
rables, pero puede ser destruido en menos de un minuto por los desinfectantes comunes como hipoclorito de sodio, peróxido de hidrógeno, etc. La infección es adquirida ya sea por la inhalación de estas gotículas o tocando las superficies contaminadas y posteriormente la nariz, boca y ojos. El virus también puede encontrarse en heces y agua contaminada además de que puede ser transmitido por aerosoles. El período de incubación varía desde 2 hasta 14 días siendo la media de 5 días (Huang et al., 2020; Wiersinga et al., 2020).

\section{Diagnóstico}

El diagnóstico diferencial incluye todo tipo de infección respiratoria viral como influenza, parainfluenza, virus sincitial respiratorio (RSV, por sus siglas en inglés), adenovirus, metapneumovirus humano, coronavirus no COVID-19 y organismos atípicos como micoplasma y clamidia, además de infecciones bacterianas. Si no es posible diferenciar COVID-19 de estas infecciones por medio de la clínica o a través de pruebas de laboratorio, la historia de viajes recientes toma una gran relevancia (Wiersinga et al., 2020). Las pruebas deben hacerse a muestras respiratorias inmediatamente al presentarse la sospecha de infección.

El diagnóstico de COVID-19 se hace generalmente a través de reacción en cadena de la polimerasa con transcriptasa reversa (RT-PCR) realizada en muestras respiratorias nasofaríngeas u orofaríngeas. La sensibilidad de las pruebas varía dependiendo del tiempo de exposición del paciente. Aspectos como sensibilidad y especificidad deben considerarse al momento de elegir la prueba que se utilizará para el diagnóstico. Algunos factores que contribuyen a la obtención de resultados falsos negativos son la técnica de colección de muestras, tiempo de exposición al virus y la fuente de la muestra, pues aquellas obtenidas del tracto respiratorio inferior son más sensibles que las del tracto respiratorio superior (Wiersinga et al., 2020). SARS-CoV-2 puede ser detectado en heces, pero no en orina. La saliva puede ser una muestra alternativa que requiera menos equipo de protección personal y de toma de muestra, pero se requiere muchos más estudios de validación de las pruebas que la utilizan (Guo et al., 2020; Sapkota et al., 2020; Wiersinga et al., 2020).

Muchas pruebas serológicas pueden servir para apoyar el diagnóstico y medir la respuesta inmunológica el virus. Sin embargo, la presencia de anticuerpos no necesariamente indica inmunidad, pues no todos los anticuerpos producidos en respuesta a la infección son neutralizantes (Zhou \& Zhao, 2020). Aún se desconoce si existe reinfección por coronavirus, pues la presencia de anticuerpos cambia la susceptibilidad a la infección, pero aún no se sabe por cuánto tiempo confiere inmunidad protectora. Los anticuerpos IgM son detectables en los primeros 5 días de la infección manteniéndose niveles detectables durante 2-3 semanas de la enfermedad, la respuesta IgG se empieza a detectar aproximadamente 14 días después del aparecimiento de síntomas. Los títulos altos de anticuerpos pueden observarse en formas más agresivas de la enfermedad. Existen muchas pruebas serológicas disponibles e inmunoensayos automatizados, pero con sensibilidad y especificidad variable, por lo que deben continuarse los estudios de validación y verificación antes de concluir sobre la utilidad de alguna en particular (Guo et al., 2020; Wiersinga et al., 2020).

\section{Pruebas de laboratorio para detectar la infección por SARS-CoV-2 y monitoreo de pacientes}

\section{Pruebas moleculares para la detección de SARS-CoV-2}

Las pruebas que se utilizan para el diagnóstico inicial de COVID-19, son las pruebas de amplificación de ácidos nucleicos (NAAT, por sus siglas en inglés) (Caliendo \& Hanson, 2020; Tang et al., 2020), siendo la RT-PCR, considerada por algunos autores el estándar de oro para la detección del ARN del virus (Younes et al., 2020).

De acuerdo con la Guía de Diagnóstico de COVID-19 de la Sociedad de Enfermedades Infecciosas de Estados Unidos (IDSA, por sus siglas en inglés), los NAAT han jugado un papel crítico en la respuesta global a la pandemia del COVID-19, ya que son necesarias para la toma de decisiones sobre el manejo de los pacientes, los programas de prevención y control de infecciones en servicios sanitarios y las respuestas de salud pública (Hanson et al., 2020).

Estas pruebas utilizan como muestras especímenes del tracto respiratorio superior siendo estos, hisopado nasofaríngeo, hisopado nasal o hisopado orofaríngeo, recolectados todos estos por un profesional de salud. Así mismo, en pacientes con enfermedad del tracto respiratorio inferior, muestras como esputo, aspirado traqueal o broncoalveolar pueden utilizarse para las pruebas NAAT y pueden recolectarse durante 
el momento de la intubación. Para todas las pruebas NAAT que utilicen estos últimos especímenes, los laboratorios deben realizar la evaluación de desempeño o verificación previo a su implementación, debido a que la mayoría de NAAT cuentan únicamente con autorización por emergencia (Alhazzani et al., 2020; Caliendo \& Hanson, 2020).

Dentro de las pruebas moleculares disponibles en el mercado nacional que cuentan con aprobación por uso de emergencia, la mayoría se basan en dos metodologías principales, RT-PCR y la amplificación isotérmica mediada por bucles (LAMP por sus siglas en inglés) (Younes et al., 2020; MSPAS, 2020a).

La secuenciación de genoma completo (WGS, por sus siglas en inglés) puede apoyar estudios de epidemiología molecular, el cultivo viral no es recomendado como un procedimiento de diagnóstico (Konukoglu, 2020).

Utilidad de las pruebas moleculares. De acuerdo con la guía UpToDate un resultado positivo en una prueba NAAT confirma el diagnóstico de la COVID-19 y no es necesario realizar pruebas adicionales. Sin embargo, dependiendo de los protocolos, puede que sean necesarias pruebas NAAT adicionales para el monitoreo de pacientes hospitalizados. Respecto al seguimiento de pacientes como criterio para recuperación no son recomendables, ya que existe evidencia que pacientes recuperados pueden tener ARN detectable en especímenes respiratorios luego del establecimiento de síntomas sin que esto signifique que continúen siendo infecciosos (Caliendo \& Hanson, 2020).

La Guía de Diagnóstico de COVID-19 de la IDSA recomienda evaluar con NAAT a todos los pacientes sintomáticos, sin embargo, en caso de desabastecimiento tanto de reactivos como de insumos para la toma de muestra y escasez de EPP, puede existir necesidad de priorizar las pruebas y dirigirlas a grupos de alto riesgo, estrategia que ha adoptado el Centro Nacional de Epidemiología del MSPAS (Hanson et al., 2020, MSPAS, 2020c).

RT-PCR. Es una prueba molecular de amplificación de ácidos nucleicos utilizada para la obtención de múltiples copias de una secuencia de ADN antes a su detección. Dado que el SARS-CoV-2 es un virus de $A R N$, este debe sufrir una retrotranscripción previo a su replicación mediante PCR, sintetizando ADN copia (cADN). Teóricamente, esto será posible únicamente si el ARN del virus SARS-CoV-2 se encuentra presente (Corman et al., 2020). La RT-PCR puede ser interpre- tada de forma semicuantitativa correlacionando la velocidad con que se emite la señal de la amplificación con la cantidad y calidad del material genético inicial (Green et al., 2020).

Para la realización de una rRT-PCR es necesario realizar una extracción de ácidos nucleicos, retrotranscripción y amplificación utilizando un set de primers y sondas (probes), demás insumos para la reacción (ADN polimerasa, transcriptasa reversa, dNTPs, solución amortiguadora) y un termociclador en tiempo real, equipo que permite, adicionalmente, su detección mediante la emisión de una señal de fluorescencia. El tiempo aproximado para el procesamiento de una muestra por RT-PCR es de 4 a 6 h (Corman et al., 2020).

El genoma del SARS-CoV-2 consiste en 29,811 pares de bases y 15 genes, de estos las dianas moleculares para los ensayos de amplificación incluyen el gen E, N, RdRp (ARN dependiente ARN polimerasa) incluido dentro del gen $\mathrm{S}$ (spike) u otras dianas dentro de la región ORFab (del inglés open reading frame) que codifica tanto para la polimerasa como para la helicasa. Por lo general, los ensayos de amplificación utilizan dos o tres de estas dianas, algunos protocolos utilizando una como tamizaje y la segunda o tercera como confirmación. En Figura 2 y Tabla 2 se encuentra un resumen de los protocolos desarrollados por los laboratorios de referencia de la OMS, las dianas moleculares que detectan y la interpretación de sus resultados ( $\mathrm{Lim}$ $\&$ Lee, 2020).

En general las pruebas rRT-PCR tienen una alta sensibilidad analítica con un límite de detección que varía de 100 a 1,000 copias y una muy elevada especificidad. Sin embargo, numerosos estudios han demostrado que una o más pruebas negativas de RT-PCR no descartan la infección por el SARS-CoV-2 (Konukoglu et al., 2020).

A pesar de su alta sensibilidad analítica, la sensibilidad clínica de este ensayo suele ser inferior por varios factores como errores durante las fases preanalítica y analítica. Entre estos cabe mencionar los producidos por sobrecarga de trabajo, inadecuada toma de muestra, transporte o almacenamiento, recolección del espécimen inadecuado, errores de pipeteo o contaminación cruzada, toma de muestra posterior a terapia antirretroviral, ventana de diagnóstico y mutaciones en los sitios de las dianas moleculares del ensayo analítico (Lippi et al., 2020).

Es importante mencionar como limitaciones adicionales del método, que el qRT-PCR muchas veces es caro, requiere personal altamente entrenado y especia- 


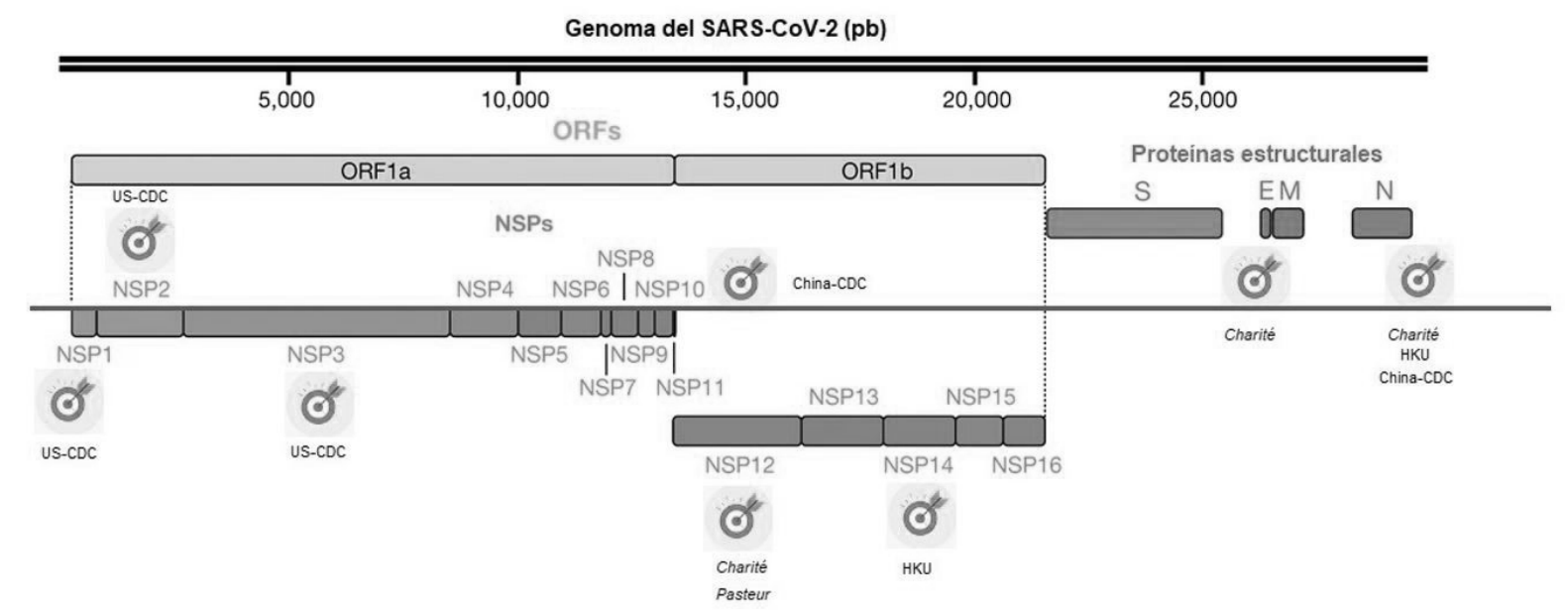

Figura 2. Genoma del SARS-CoV-2 y dianas moleculares de diferentes protocolos desarrollados por laboratorios de referencia de la OMS. Nota. Adaptado de "Molecular and antibody point-of-care tests to support the screening, diagnosis and monitoring of COVID-19” K. Green, S. Graziadio, P. Turner, T. Fanshawe, \& J. Allen, J., 2020

Tabla 2

Dianas moleculares detectadas por diferentes protocolos desarrollados por laboratorios de referencia de la OMS

\begin{tabular}{|c|c|c|c|}
\hline Ensayo (País) & Dianas moleculares & Criterios diagnósticos & Referencia \\
\hline \multirow[t]{3}{*}{ (Alemania) } & $\mathrm{RdRp}$ & \multirow{3}{*}{$\begin{array}{l}\text { Amplificación de gen E tamizaje; } \\
\text { amplificación de gen RdRp } \\
\text { confirmación para SARS-CoV-2. }\end{array}$} & \multirow[t]{3}{*}{ Coreman et al., 2020} \\
\hline & E & & \\
\hline & $\mathrm{N}$ & & \\
\hline \multirow[t]{2}{*}{ HKU (Hong Kong) } & ORF1b-nsp14 & \multirow{2}{*}{$\begin{array}{l}\text { Amplificación de gen N tamizaje; } \\
\text { amplificación de gen ORF1b-nsp14 } \\
\text { confirmación para SARS-CoV-2 }\end{array}$} & \multirow{2}{*}{$\begin{array}{l}\text { LKS Faculty of } \\
\text { Medicine School of } \\
\text { Public Health. } 2020 .\end{array}$} \\
\hline & $\mathrm{N}$ & & \\
\hline \multirow[t]{2}{*}{ China CDC (China) } & $\mathrm{N}$ & \multirow{2}{*}{$\begin{array}{l}\text { Amplificación de gen N tamizaje; } \\
\text { amplificación de gen ORF1b-nsp10 } \\
\text { confirmación para SARS-CoV-2 }\end{array}$} & \multirow{2}{*}{$\begin{array}{l}\text { National Health } \\
\text { Commission of China, } \\
2020\end{array}$} \\
\hline & ORF1ah-nsn10 & & \\
\hline \multirow[t]{3}{*}{$\begin{array}{l}\text { EEUU CDC } \\
\text { (Estados Unidos) }\end{array}$} & $\mathrm{N} 1$ & \multirow{3}{*}{$\begin{array}{l}\text { Amplificación de N1 y N2 } \\
\text { confirmación para SARS-CoV-2 }\end{array}$} & \multirow{3}{*}{$\begin{array}{l}\text { Centro para el Control y } \\
\text { Prevención de Enferme } \\
\text { dades, 2020d. }\end{array}$} \\
\hline & N2 & & \\
\hline & N3 & & \\
\hline \multirow[t]{2}{*}{$\begin{array}{l}\text { Instituto Pasteur, } \\
\text { Paris (Francia) }\end{array}$} & RdRp IP2 (FIo2) & \multirow[t]{2}{*}{$\begin{array}{l}\text { Amplificación de RdRpIP2 y RdRpIP4 } \\
\text { confirmación para SARS-CoV-2 }\end{array}$} & \multirow[t]{2}{*}{ Etievant et al., 2020} \\
\hline & RdRp IP4 (FIo4) & & \\
\hline
\end{tabular}


lizado requiriendo de equipo sofisticado para la amplificación y detección del genoma viral. Esto implica que la técnica no está diseñada para aplicaciones a gran escala en áreas con recursos limitados, lo cual impacta de forma negativa el establecimiento de programas de control de infecciones (Hanson et al., 2020).

RT-LAMP. Esta metodología tiene como ventaja que puede realizarse con o sin el uso de un termociclador y es útil para el diagnóstico de enfermedades infecciosas en servicios de salud que tengan limitación de recursos. El fundamento de la técnica consiste en el uso de una ADN polimerasa con elevada actividad de desplazamiento de la hebra que también posee actividad de transcriptasa reversa. Esto permite que la amplificación de ARN viral se realice en un solo paso a temperatura constante (Kitagawa et al., 2020).

Los RT-LAMP tiene como ventaja adicional que produce resultados rápidos (entre 30 y $60 \mathrm{~min}$ ). Adicionalmente, a diferencia del rRT-PCR, los productos de amplificación generados por el RT-LAMP pueden detectarse por turbidimetría, colorimetría o fluorescencia (Kitagawa et al., 2020). Varios estudios han demostrado que esta técnica tiene un límite de detección de 100 copias/reacción, haciéndola una técnica altamente sensible y valiosa para el diagnóstico comparable en desempeño con el rRT-PCR (Park et al., 2020; Yan et al., 2020).

Considerando sus ventajas de amplificación rápida, operación simple, bajo costo, alta sensibilidad y especificidad, la metodología RT-LAMP tiene aplicaciones no solamente para diagnóstico clínico, sino que también para la vigilancia de enfermedades infecciosas en países en vías de desarrollo (Kashir \& Yaquniddin, 2020).

Pruebas de punto de atención (POCT). Son técnicas diseñadas para su aplicación donde se requiera el procesamiento de una gran cantidad de muestras en un tiempo corto (aproximadamente 1 hora) y que no cuenten con equipo especializado para la realización de pruebas moleculares o bien, con personal capacitado en dichos análisis. Son especialmente útiles para el tamizaje de pacientes en servicios de emergencia (Perera, 2020).

NAAT tipo POCT. Por ser comunes en el país, dentro de este tipo de pruebas cabe mencionar los sistemas cerrados de análisis molecular. Son sistemas que integran la extracción de ARN viral, su amplificación y detección dentro de un cartucho. La sencillez del proceso no requiere un entrenamiento intensivo del personal ni de equipos adicionales al utilizado para su amplificación y detección. Adicionalmente, utilizando el equipo de protección adecuado, la literatura refiere que pueden ser procesadas, aunque no se cuente con una cabina de bioseguridad clase II. Una de las principales desventajas de este tipo de análisis es asegurar su abastecimiento debido a la alta demanda provocada por la pandemia (Perera, 2020).

Pruebas de diagnóstico rápido para detección de antígenos (PDR). Las pruebas de antígenos son inmunoensayos que detectan la presencia de proteínas virales y han sido utilizadas para detectar infección activa en el caso de otros patógenos respiratorios como Influenza y (Centro para el Control y Prevención de Enfermedades [CDC], 2020b).

En el caso del virus SARS-CoV-2, PDR han sido diseñadas para detectar proteínas virales que son producidas por el virus en replicación en muestras respiratorias en puntos de atención al paciente. La mayoría de este tipo de pruebas utiliza un ensayo tipo sándwich que ocurre en una matriz de nitrocelulosa que contiene anticuerpos contra el complejo antígeno-conjugado en una región en específica conocida como línea prueba y una región con anticuerpos anti-conjugado conocida como línea control (World Health Organization [WHO], 2020).

Estas pruebas tienen las ventajas de poder realizarse de forma sencilla, en laboratorios o servicios sanitarios de baja complejidad y dan un resultado rápido (10 a 30 min). Estas características permiten mejorar el acceso a pruebas y disminuyen el tiempo de respuesta, pudiendo utilizarse como una estrategia para la descentralización de pruebas en pacientes sintomáticos (Centro Nacional de Epidemiología, 2020; WHO, 2020). Sin embargo, de forma general, el desempeño analítico de estas pruebas es inferior al de pruebas de biología molecular, principalmente su sensibilidad, por lo que la interpretación de sus resultados y desarrollo de guías para diagnóstico es esencial para garantizar su uso adecuado (Centro Nacional de Epidemiología, 2020).

De acuerdo con el desempeño analítico y clínico (elevada especificidad) que las pruebas de antígeno han demostrado en población definida como caso sospechoso, se puede diagnosticar una infección activa por COVID-19 con un resultado positivo en este tipo de pruebas (CDC, 2020b; Centro Nacional de Epidemiología, 2020; WHO, 2020). De acuerdo con la OMS, utilizarlas e interpretarlas adecuadamente pueden apoyar sustancialmente al manejo de la crisis sanitaria en el 
manejo de pacientes y en la toma de decisiones y vigilancia desde un punto de salud pública (WHO, 2020).

Dado que el desempeño analítico de las PDR para COVID-19 puede variar entre marcas de pruebas, las recomendaciones de la OMS indican que deben tener como mínimo una sensibilidad analítica mayor al $80 \%$ y una especificidad de más del 97\% (WHO, 2020).

En Guatemala, las PDR para COVID-19 se introdujeron tempranamente en la pandemia, dentro de un algoritmo que las utiliza en pacientes sintomáticos (casos sospechosos). Un resultado positivo confirma la infección y dada su sensibilidad analítica, un resultado negativo no la descarta, por lo que debe ser confirmado por una prueba NAAT. Dicho algoritmo ahora es sugerido por la OMS para países en los que la capacidad para realizar NAAT es reducida (Centro Nacional de Epidemiología, 2020; WHO, 2020).

\section{Pruebas serológicas para la detección de infección por SARS-CoV-2}

Aunque la RT-PCR es una prueba muy sensible también tiene sus limitaciones, esta no puede responder a un brote a largo plazo, dado que estas pruebas detectan la presencia del agente infeccioso y no pueden proporcionar un resultado de diagnóstico para alguien que haya sido infectado previamente y que se haya recuperado de la infección. Esto hace que una prueba serológica bien fundamentada sea una necesidad como prueba complementaria o de apoyo a la molecular. El uso principal de las pruebas de anticuerpos es ayudar a comprender las respuestas inmunes al SARS-CoV-2 de forma cualitativa o cuantitativa e identificar a las personas infectadas en comparación con las que no.

Los datos de las pruebas serológicas son esenciales para conocer la epidemiología del virus (Loeffelholz \& Tang et al., 2020) y para determinar el estado inmune de la población y de los trabajadores de salud. Aquellos que han desarrollado los anticuerpos pueden desplegarse nuevamente al trabajo de primera línea con menos riesgo de enfermedad, pero estas pruebas no deben de ser concluyentes para guiar el uso del equipo de protección personal (EPP) o el cumplimiento de las prácticas de distanciamiento social. También se necesitan ensayos serológicos para realizar estudios epidemiológicos y evaluar el grado de propagación del virus en comunidades y determinar la tasa de mortalidad por infección. Los ensayos serológicos pueden identificar a las personas como posibles donantes de plasma con anticuerpos para tratar personas enfermas y además, se pueden utilizar para seleccionar pacien- tes con ensayos clínicos para vacunas o desarrollo de terapia (CDC, 2020a).

Las pruebas serológicas detectan la infección en etapa tardía o pasada por el virus del SARS-CoV-2, midiendo la respuesta inmune humoral del huésped al virus. La primera línea de defensa durante las infecciones virales es la inmunoglobulina $\mathrm{M}(\operatorname{IgM})$ antes de la generación de inmunoglobulina $\mathrm{G}$ ( $\mathrm{IgG}$ ) como respuesta adaptativa, siendo la segunda importante para la inmunidad a largo plazo (European Commission, 2020). Se ha encontrado que los pacientes COVID-19 producen anticuerpos en un patrón similar. La Figura 3 muestra la cinética de las inmunoglobulinas durante la infección por COVID-19 y las fases de la enfermedad. El conocimiento de estas es muy importante para determinar la evolución de la enfermedad y utilizar las pruebas serológicas como apoyo en un tiempo adecuado.

Es muy importante que la metodología a utilizar para la detección de anticuerpos, como prueba para apoyo al diagnóstico, pueda diferenciar entre $\operatorname{IgM}$ e IgG ya que proporciona un continuo de datos desde la infección hasta la recuperación.

La presencia de IgM se produce entre los 7-10 días del inicio de los síntomas y suele disminuir a partir de los 20 días, hasta desaparecer. La IgG se positiviza a partir de los 14-20 días y suele mantenerse durante un tiempo prolongado (Diaz-Castrillón et al., 2020). Por lo tanto, el diagnóstico de infección de COVID-19 basado en pruebas serológicas en la mayoría de los casos solo será posible en la fase de recuperación o convalecencia, cuando muchas de las oportunidades de intervención clínica o interrupción de la transmisión de la enfermedad ya han pasado.

Para mejorar la eficacia del diagnóstico se deben utilizar las pruebas serológicas, pero estas pruebas no deben utilizarse como única herramienta para el diagnóstico, debido a que hay un retraso temporal entre la exposición al virus y el desarrollo de anticuerpos por parte del sistema inmunitario y los anticuerpos persistirán mucho después de que el cuerpo haya eliminado una infección (Jacofsky et al., 2020). La detección de anticuerpos en combinación con RT-PCR amplía la ventana de detección de la infección por SARS-CoV-2 minimizando los resultados falsos positivos y falsos negativos. Para su aplicación es importante conocer e interpretar correctamente la combinación de estas pruebas. En la Tabla 3 se presenta la interpretación general de Infección Viral/Anticuerpo.

Para la selección de pruebas de anticuerpos es necesario recordar que el coronavirus tiene cuatro proteínas estructurales principales: N, S, M y E. La 


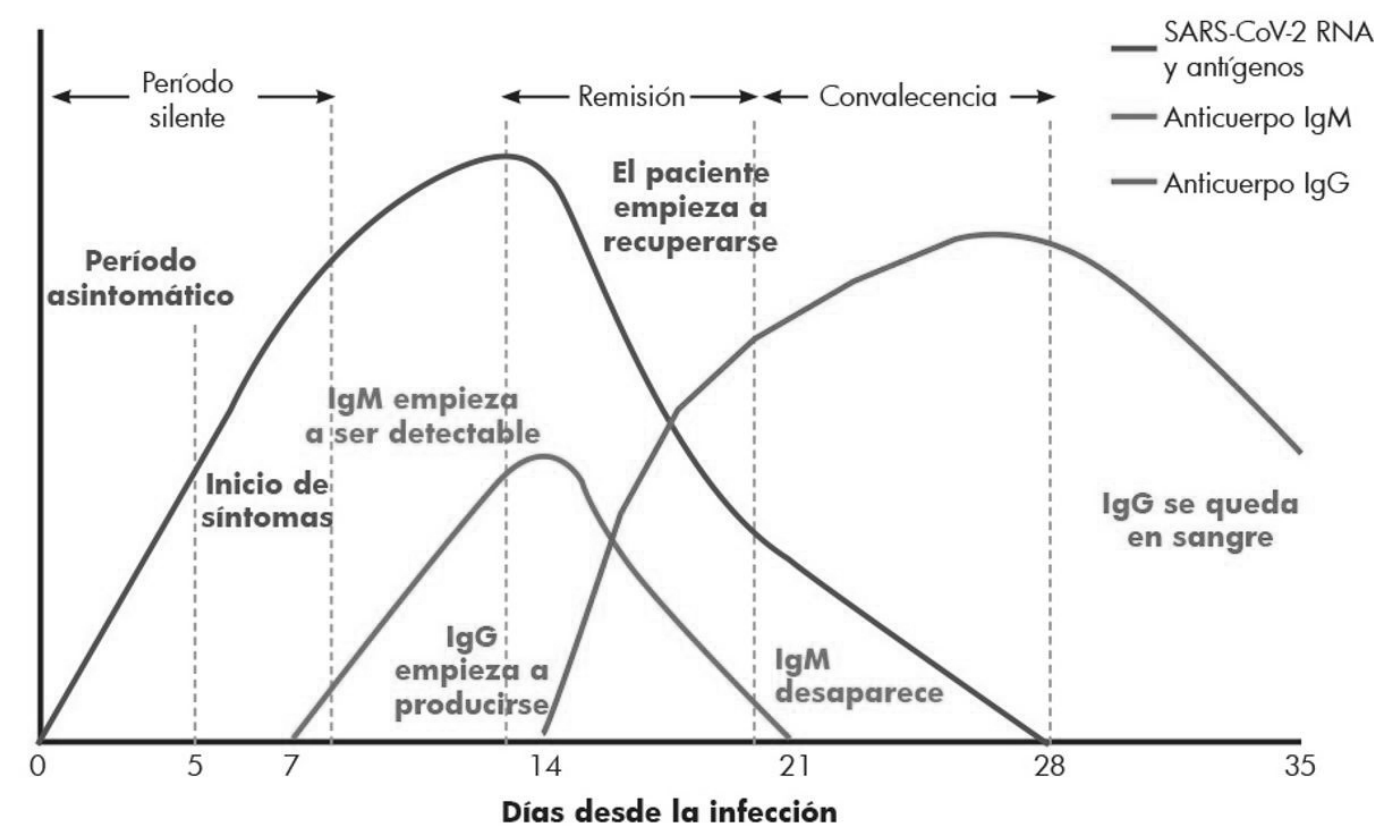

Figura 3. Cinética de las inmunoglobulinas durante la infección por SARS-CoV-2 y etapas de la enfermedad. Nota. Adaptado de "Current performance of COVID-19 test methods and devices and proposed performance criteria” por European Commission, 2020, p.)

Tabla 3

Interpretación General de Infección Viral

\begin{tabular}{|c|c|c|c|}
\hline \multicolumn{3}{|c|}{ Resultado de la prueba } & \multirow{2}{*}{ Interpretación General } \\
\hline ARN & $\operatorname{IgM}$ & $\operatorname{IgG}$ & \\
\hline+ & - & - & Periodo inicial de la infección \\
\hline+ & + & - & Fase activa de la infección. Paciente ha desarrollado anticuerpos \\
\hline- & + & - & $\begin{array}{l}\text { El paciente puede estar en etapa temprana de la infección. El resultado de ARN } \\
\text { puede ser falso negativo o IgM falso positivo }\end{array}$ \\
\hline+ & + & + & Fase activa de la infección. Respuesta inmune ha progresado \\
\hline+ & - & + & $\begin{array}{l}\text { El paciente está en etapa tardía de la Infección o ha desarrollado una infección } \\
\text { recurrente }\end{array}$ \\
\hline- & + & + & El paciente en etapa tardía de la infección o ARN falso negativo \\
\hline- & - & + & El paciente puede haberse recuperado o ha sido infectado en el pasado \\
\hline
\end{tabular}

Nota. + se refiere a resultado positivo, - se refiere a resultado negativo. 
proteína S consiste en las subunidades $\mathrm{S} 1$ y S2. $\mathrm{La}$ subunidad S1 de la cabeza globular contiene el dominio de unión al receptor (RBD, por sus siglas en inglés) y facilita la unión a las células huésped. La subunidad S2 comprende el tallo de la proteína espiga y facilita la fusión entre la envoltura viral y la membrana de la célula. La proteína $S$ es altamente inmunogénica ya que se encuentra en la superficie del virus (DiazCastrillón, 2020).

La proteína $\mathrm{N}$ juega un papel importante en la transcripción y replicación del ARN viral. Esta se expresa abundantemente durante las infecciones y también tiene una alta actividad inmunogénica. Por lo tanto, tanto la proteína $\mathrm{N}$ como la $\mathrm{S}$ podrían ser objetivos potenciales para la detección basada en anticuerpos de SARS-CoV (Meyer et al., 2014). Sin embargo, la homología de la proteína $\mathrm{N}$ entre SARSCoV-2 y SARS-CoV-1 es del 90\%, en comparación con el proteína $\mathrm{S}(77 \%)$, además la proteína $\mathrm{N}$ presenta un mayor porcentaje de identidad de aminoácidos entre otros coronavirus endémicos (OC43, HKU1, 229E, NL63) y MERS-CoV, en comparación con la subunidad $\mathrm{S}$, lo que sugiere que las pruebas serológicas que usan proteína $\mathrm{N}$ podrían presentar mayor porcentaje de falsos positivos por reactividad cruzada entre los coronavirus endémicos, pero podrían ser más sensibles. Sin embargo, los anticuerpos dirigidos contra la proteína de unión a los receptores celulares (proteína S) suelen ser más específicos. Por esto, utilizar ensayos que detecten anticuerpos IgG o IgM dirigidos contra los dos antígenos combinados hace que las pruebas serológicas tengan un mejor desempeño (Meyer et al., 2014).

Antes de iniciar el uso de la prueba serológica seleccionada, se debe asegurar que esta cuenta con aprobaciones internacionales y posteriormente debe de evaluarse su desempeño en la población en la que se utilizará, esto con el fin de evitar inconvenientes derivados de ensayos serológicos no validados que pueden implicar riesgo de falsos negativos, si se realizan de manera temprana, especialmente en enfermedades leves; o bien riesgos de resultados falsos positivos, particularmente con pruebas de IgM y reactividad cruzada con coronavirus del resfriado común (por ejemplo, HKU1, NL63, OC43, 229E) (Infectious Diseases Society of America, 2020).

Por lo tanto, al utilizar una prueba, debe de corroborarse su sensibilidad o capacidad de detectar casos positivos verdaderos, su especificidad o capacidad de detectar verdaderos casos negativos y su especificidad analítica o reactividad cruzada. Además si las pruebas serológicas tienen como objetivo la toma de decisiones para regreso a la normalidad o para guiar las acciones de las personas en torno a la salud y seguridad del paciente, será fundamental que tanto la sensibilidad como la especificidad sean lo más altas posible para evitar resultados incorrectos (2020a).

Algunas de las pruebas serológicas que cuentan con aprobación de la Administración de Drogas y Medicamentos (FDA) de emergencia, son: Abbott Architect IgG, Abbott Alinity IgG, Prueba Rápida Autobio Anti SARS-COV-2, Biorad Platelia SARSCOV-2 anticuerpos totales, Diasorin LIAISON IgG, entre otras. Cabe mencionar que estas son aprobaciones de emergencia, lo que indica que estas pruebas deben de seguir sometiéndose a estudios de perfeccionamiento para mejorar su desempeño (U.S. Food \& Drug, 2020).

\section{Pruebas complementarias para el diagnóstico y monitoreo de pacientes con infección por SARS-CoV-2}

Existe evidencia científica sobre la utilidad de ciertas pruebas de laboratorio para el seguimiento y evaluación del paciente con COVID 19. La interpretación de estas pruebas es fundamental para evaluar la gravedad y progresión de la enfermedad, así como para seguimiento de la intervención terapéutica.

Las características de laboratorio más comunes informadas en pacientes con COVID-19, incluyen cambios hematológicos como, incremento en la velocidad de eritrosedimentación, leucopenia y linfopenia en un $85 \%$ de los pacientes, acidosis láctica relacionada con la hipoxia tisular (Hurtado Bredda \& Rando, 2000), aumento de creatinina y nitrógeno de urea, sobre todo en los pacientes más graves, aumento de la deshidrogenasa láctica, marcador de daño tisular; disminución de albumina, niveles elevados de aspartato aminotransferasa, alanina aminotransferasa y creatina quinasa (Abbasi-Oshagui et al., 2020). Otro hallazgo de laboratorio importante para el seguimiento de pacientes con COVID-19 asociado con inflamación es el incremento en proteína $\mathrm{C}$ reactiva (PCR), la cual incrementa significativamente en las fases iniciales de la infección, especialmente en aquellos con cuadro grave para lo cual, es importante destacar que la PCR se ha asociado con el desarrollo de la enfermedad y es un predictor temprano de COVID-19 grave (Ponti et al., 2020).

Entre los marcadores inmunológicos se puede observar un incremento de interleucina-6 (IL-6) y 
ferritina sérica. Estos marcadores aumentan significativamente en los pacientes que presentan mayor gravedad. El aumento significativo de citocinas inflamatorias como IL-6, está relacionado con la "tormenta de citocinas", lo que puede provocar más daño tisular. La IL-6 puede ser eficazmente bloqueada por el Tocilizumab medicamento utilizado en los pacientes graves (Zhang et al., 2020). Por otro lado, los niveles elevados de ferritina están asociados al pronóstico del paciente (Ponti et al., 2020). Además, se ha observado una elevación asociada a severidad y mortalidad de los marcadores cardiacos y del dímero $\mathrm{D}$, marcador de generación de trombina y fibrinólisis en la activación de la coagulación, proceso observado en pacientes con COVID-19 (Ponti et al., 2020). Tanto el dímero D como los marcadores cardiacos son cruciales en la monitorización de pacientes graves. En la Tabla 4 se resume el significado clínico de los valores anormales en parámetros de laboratorio para pacientes COVID-19.

\section{Conclusiones}

La actual pandemia de COVID-19 es una seria amenaza para la salud pública. Han existido avances importantes respecto a la información que se cuenta de la enfermedad y el patógeno que la causa, el SARSCoV-2. Esto ha sido importante pues ha permitido a epidemiólogos, clínicos y laboratoristas el desarrollar algoritmos diagnósticos que permiten la rápida iden- tificación de casos, su monitoreo y de esta manera controlar brotes epidémicos.

Las primeras pruebas de laboratorio desarrolladas para el diagnóstico de COVID-19 se basan en la detección molecular (RT-PCR) de genes específicos del SARS-CoV-2, sin embargo, para ser realizadas requieren de laboratorios de alta complejidad, equipo especializado y personal entrenado lo que las hace difícil de implementar en países en vías de desarrollo y con poco acceso tecnológico en salud.

A pocos meses de la pandemia se desarrollaron las pruebas rápidas de detección de antígeno (proteínas del virus) que permitieron que laboratorios de mediana o baja complejidad pudieran realizar el diagnóstico de COVID-19 de manera rápida con el inconveniente de presentar baja sensibilidad, por lo que es necesario la confirmación de los resultados negativos por medio de una prueba de detección molecular. Desde el mes de junio el Ministerio de Salud Pública de Guatemala ha incorporado a sus algoritmos diagnósticos el uso de pruebas rápidas de antígeno.

Las pruebas de detección de anticuerpos contra el SARS-CoV-2 han mostrado tener poca utilidad para el diagnóstico o monitoreo de la enfermedad. En Guatemala su uso ha sido autorizado por las guías epidemiológicas exclusivamente para estudios de seroprevalencia en la población y su uso en bancos de sangre que procesen plasma convaleciente de pacientes recuperados de COVID-19.

Tabla 4.

Significado clínico de valores anormales de parámetros de laboratorio en pacientes con Covid-19

\begin{tabular}{ll} 
Parámetro & \multicolumn{1}{c}{ Significado } \\
\hline Linfopenia & Disminución de la respuesta inmunológica frente al virus \\
Creatinina y nitrógeno de urea aumentados & Daño renal \\
Deshidrogenasa láctica aumentada & Daño pulmonar o hepático diseminado \\
Albumina disminuida & Deterioro función hepática \\
Transaminasas aumentadas & Daño hepático u orgánico \\
Proteína C reactiva aumentada & Infección viral severa \\
Interleucina 6 Aumentada & Daño tisular por tormenta de citocinas \\
Dímero D aumentado & Activación de la coagulación sanguínea o coagulopatía \\
Troponina aumentada & Daño cardiaco \\
\hline
\end{tabular}




\section{Referencias}

Abbasi-Oshagui, E., Mirzael, F., Farahani, F., Khodadadi, I., \& Tayebinia, H. (2020)., Diagnosis and treatment of coronavirus disease 2019 (COVID-19): Laboratory, PCR. and chest CT imaging findings. International Journal of Surgery, 79, 143-153. https://doi.org/10.1016/j. ijsu.2020.05.018

Alhazzani, W., Møller, M. H., Arabi, Y. M., Loeb, M., Gong, M. N., Fan, E., ... Rhodes, A. (2020). Surviving Sepsis Campaign: Guidelines on the management of critically ill adults with Coronavirus Disease 2019 (COVID-19). Intensive Care Medicine, 46, 854-887. https:// doi.org/10.1007/s00134-020-06022-5

Caliendo, A. M., \& Hanson, K. E. (2020, July 10). Coronavirus disease 2019 (COVID-19): Diagnosis. Recuperado el 19 de julio 2020 de https://www.uptodate.com/contents/coronavirusdisease-2019-covid-19-diagnosis.

Centro de Control y Prevención de Enfermedades de Corea del Sur. (11 de Julio 2020).Patient Treatment \& Management. Recuperado el 11 de julio 2020 de http://ncov.mohwgo.kr/en/baroView.do?brdId= $11 \&$ brdGubun $=112 \&$ dataGubun $=\&$ ncvContSq $=\&$ contSeq $=\&$ board_id $=\&$ gubun $=$

Centro para el Control y Prevención de Enfermedades (2020a). Antibody testing guidelines. Recuperado el 23 de mayo de 2020 de https://www.cdc.gov/ coronavirus/2019-ncov/lab/resources/antbodytests-guidelines.html

Centro para el Control y Prevención de Enfermedades (2020b). Interim Guidance for Rapid Antigen Testing for SARS-CoV-2. Recuperado el 01 de octubre de 2020 de https://www.cdc.gov/ coronavirus/2019-ncov/lab/resources/antigentests-guidelines.html

Centro para el Control y Prevención de Enfermedades (2020c). Overview of Testing for SARS-CoV-2 (COVID-19). Recuperado el 19 de julio de 2020 de https://www.cdc.gov/coronavirus/2019-ncov/ lab/rt-pcr-panel-primer-probes.html
Centro para el Control y Prevención de Enfermedades (2020d). Real-time RT-PCR Primers and Probes for COVID-19. Recuperado el 04 de octubre de 2020 de https://www.cdc.gov/coronavirus/2019ncov/lab/rt-pcr-panel-primer-probes.html

Corman, V. M., Landt, O., Kaiser, M., Molenkamp, R., Meijer, A., Chu, D. K. W., ... Drosten, C. (2020). Detection of 2019-nCoV by real-time RT-RCR. Eurosurveillance, 25(3). https://doi. org/10.2807/1560-7917.ES.2020.25.3.2000045

Diaz-Castrillón, F. J., \& Toro-Montoya, A. I. (2020). SARS-COV-2/COVID 19: El virus, la enfermedad y la pandemia. (2020). Medicina \& Laboratorio, 24(3),183-205. https://doi. org/10.36384/01232576.268

European Commission. (16 de Abril de 2020). Current performance of COVID-19 test methods and devices and proposed performance criteria. https://ec.europa.eu/docsroom/documents/40805

Etievant, S., Bal, A., Escuret, V., Brengel-Pesce, K., Bouscambert, M., Cheynet, V., ... Gaymard, A. (2020). Performance assessment of SARSCoV-2 PCR assays developed by WHO Referral Laboratories. Journal of Clinical Medicine, 9(6), 1871. https://doi.org/10.3390/jcm9061871

Goodsell, D. S., Voigt, M., Zardecki, C., \& Burley, S. K. (2020). Integrative illustration for coronavirus outreach. PLoS Biology, 18(8), 4-10. https://doi. org/10.1371/journal.pbio.3000815

Green, K., Graziadio, S., Turner, P., Fanshawe, T., \& Allen, J. (2020). Molecular and antibody pointof-care tests to support the screening, diagnosis and monitoring of COVID-19.

Guo, Y-R., Cao, Q-D., Hong, Z-S., Tan, Y-Y., Chen, S-D., Jin, H-J., ... Yan, Y. (2020). The origin, transmission and clinical therapies on coronavirus disease 2019 (COVID-19) outbreak - an update on the status. Military Medical Research, 7(1), 11. https://doi.org/10.1186/s40779-020-00240-0

Hanson, K. E., Caliendo, A. M., Arias, C. A., Englund, J. A., Lee, M. J., Loeb, M., ... Mustafa, R. A. (2020). Infectious Diseases Society of America Guidelines on the Diagnosis of COVID-19. Clinical Infectious Diseases, 16, ciaa760.https:// doi.org/10.1093/cid/ciaa760 
Huang, C., Wang, Y., Li, X., Ren, L., Zhao, J., Hu, Y., ... Cao, B. (2020). Clinical features of patients infected with 2019 novel coronavirus in Wuhan, China. Lancet, 395(10223), 497-506. https://doi. org/10.1016/S0140-6736(20)30183-5

Hurtado Bredda, F. J., \& Rando, K. (2000). Acidosis láctica y metabolismo del lactato en paciente critico. Paciente Crítico, 13, 23-42. https:// pesquisa.bvsalud.org/portal/resource/pt/lil-351108

Infectious Diseases Society of America. (4 de mayo de 2020). Covid Antibody Testing primer. https:// www.idsociety.org/globalassets/idsa/publichealth/covid-19/idsa-covid-19-antibody-testingprimer.pdf

Jacofsky, D., Jacofsky, E., \& Jacofsky, M., (2020). Understanding antibody testing for COVID-19. The Journal of Arthroplasty, 35(7), S74-S81. https://doi.org/10.1016/j.arth.2020.04.055

Johns Hopkins University. (2020). https://coronavirus. jhu.edu/map.html

Kashir, J., \& Yaqinuddin, A. (2020). Loop mediated isothermal amplification (LAMP) assays as a rapid diagnostic for COVID-19. Medical Hypotheses, 141, 109786. https://doi.org/10.1016/j. mehy.2020.109786

Kitagawa, Y., Orihara, Y., Kawamura, R., Imai, K., Sakai, J., Tarumoto, N., ... Maeda, T. (2020). Evaluation of rapid diagnosis of novel coronavirus disease (COVID-19) using loopmediated isothermal amplification. Journal of Clinical Virology, 129, 104446. https://doi. org/10.1016/j.jcv.2020.104446

Konukoglu, D. (2020). COVID -19: Clinical and pathophysiological features and laboratory diagnosis. International Journal of Medical Biochemistry, 3(2), 47-51. https://doi.org/10.14744/ ijmb.2020.98852

Li, G., Fan, Y., Lai, Y., Han, T., Li, Z., Zhou, P., ... Wu, J. (2020). Coronavirus infections and immune responses. Journal of Medical Virology, 92(4), 424-432. https://doi.org/10.1002/jmv.25685

Lim J. \& Lee J. (2020). Current laboratory diagnosis of coronavirus disease 2019. Korean Journal of Internal Mededicine, 35(4), 741-748. https://doi. org $/ 10.3940 / \mathrm{kjim} .2020 .257$
Lippi, G., Simundic, A.-M., \& Plebani, M. (2020). Potential preanalytical and analytical vulnerabilities in the laboratory diagnosis of coronavirus disease 2019 (COVID-19). Clinical Chemistry and Laboratory Medicine, 58(7), 10701076. https://doi.org/10.1515/cclm-2020-0285

LKS Faculty of Medicine. (2020). Detection of 2019 novel coronavirus (2019-nCoV) in suspected human cases by RT-PCR

Loeffelhoz, M. J., \& Tang, Y.-W., (2020). Laboratory diagnosis of emerging human coronavirus infections - the state of the art. Emerging Microbes \& Infections, 9(1) 747-756. https://doi. org/10.1080/22221751.2020.1745095

Long, Q.-X., Tang, X.-J., Shi, Q.-L., Li, Q., Deng, H.-J., Yuan, J., ... Huang, A.-L. (2020). Clinical and immunological assessment of asymptomatic SARS-CoV-2 infections. Nature Medicine, 26(8), 1200-1204. https://doi.org/10.1038/s41591-0200965-6

Mangalmurti, N., \& Hunter, C. A. (2020). Cytokine storms: Understanding COVID-19. Immunity, 53(1), 19-25. https://doi.org/10.1016/j. immuni.2020.06.017

Meyer, B., Drosten, C., \& Muller, M., (2014). Serological assays for emerging coronaviruses: challenges and pitfalls. Virus Research,194, 175183. https://doi.org/10.1016/j.virusres.2014.03.018

Ministerio de Salud Pública y Asistencia Social. (2020a). Listado de Pruebas Registradas Autorizadas de COVID-19. Recuperado el 01 de octubre 2020 de https://medicamentos.mspas. gob.gt/index.php/descargas/pruebas-registradasautorizadas-covid-19.

Ministerio de Salud Pública y Asistencia Social. (2020b). Situación de COVID-19 en Guatemala. Guatemala. Recuperado el 19 de julio 2020 de https://tablerocovid.mspas.gob.gt/

Ministerio de Salud Pública y Asistencia Social (2020c). Vigilancia Epidemiológica de Infección Respiratoria por COVID. Recuperado de http:/ epidemiologia.mspas.gob.gt/informacion/ coronavirus-2019-ncov/descargas-coronaviruscovid-19. 
National Health Commission of China (2020). COVID-19 Laboratory Testing Guideline. China, CDC China, Beijing.

Oran, D. P., \& Topol, E. J. (2020). Prevalence of asymptomatic SARS-CoV-2 infection: A narrative review. Annals of Internal Medicine, 173(5), 362-367. https://doi.org/10.7326/M20-3012

Park, G.-S., Ku, K., Baek, S.-H., Kim, S. J., Kim, S. Il, Kim, B.-T., \& Maeng, J.-S. (2020). Development of reverse transcription loop-mediated isothermal amplification assays targeting severe acute respiratory syndrome coronavirus 2 (SARSCoV-2). Journal of Molecular Diagnostics, 22(6), 729-735. https://doi.org/10.1016/j. jmoldx.2020.03.006

Perera, N. (2020). Diagnosis of COVID-19: the present and the future. Journal of the Ceylon College of Physicians, 51(1), 48-52. http://doi.org/10.4038/ jccp.v51i1.7887

Ponti, G., Maccaferri, M., Runi, C., Tomassi, A., \& Ozben, T. (2020). Biomarkers associated with COVID-19 disease progression. Critical Reviews in Clinical Laboratory Sciences, 57(6) 389-399. https://doi.org/10.1080/10408363.2020.1770685

Sapkota, D., Thapa, S. B., Hasséus, B., \& Jensen, J. L. (2020). Saliva testing for COVID-19? British Dental Journal, 228(9), 658.659. https://doi. org/10.1038/s41415-020-1594-7

Singhal, T. (2020). A review of coronavirus disease-2019 (COVID-19). Indian Journal of Pediatrics, 87, 281-286. https://doi.org/10.1007/ s12098-020-03263-6

Sun, J., He, W.-T., Wang, L., Lai, A., Ji, X., Zhai, X. ,É Su, S. (2020). COVID-19: Epidemiology, evolution, and cross-disciplinary perspectives. Trends in Molecular Medicine, 26(5), 483-495. https://doi.org/10.1016/j.molmed.2020.02.008

Tsang, T. K., Peng, W., Lin, Y., Lau, E. H. Y., Leung, G. M., \&Cowling, B. J. (2020). Effect of changing case definitions for COVID-19 on the epidemic curve and transmission parameters in mainland China: a modelling study. Lancet, 5, e289-296. https://doi.org/10.1016/ S2468-2667(20)30089-X
U.S. Food \& Drug. (2020). EUA Authorized Serology Test Performance. Recuperado el 26 de junio 2020 en https://www.fda.gov/medical-devices/ emergency-situations-medical-devices/euaauthorized-serology-test-performance

Wiersinga, W. J., Rhodes, A., Cheng, A. C., Peacock. S. J., \& Prescott, H. C. (2020). Pathophysiology, transmission, diagnosis, and treatment of coronavirus disease 2019 (COVID-19): A review. Journal of the American Medical Association, 324(8), 782-793. https://doi.org/10.1001/ jama.2020.12839.

World Health Organization. (2020). Antigen-detection in the diagnosis of SARS-CoV-2 infection using rapid immunoassays: interim guidance, 11 September 2020. World Health Organization. https://apps.who.int/iris/handle/10665/334253.

Yan, C., Cui, J., Huang, L., Du, B., Chen, L., Xue, G., É Yuan, J. (2020) Rapid and visual detection of 2019 novel coronavirus (SARS-CoV-2) by a reverse transcription loop-mediated isothermal amplification assay. Clinical Microbiology and Infection, 26(6), 773-779. https://doi.org/10.1016/j. cmi.2020.04.001

Younes, N., Al-Sadeq, D. W., Al-Jighefee, H., Younes, S., Al-Jamal, O., Daas, H. I., É Nasrallah, G. K. (2020). Challenges in laboratory diagnosis of the novel coronavirus SARS-CoV-2. Viruses, 12(6), 582. https://doi.org/10.3390/v12060582

Zhang, C., Wu, Z., Li, J.-W., Zhao, H., \& Wang, G.-Q. (2020). Cytokine release syndrome in severe COVID-19: interleukin-6 receptor antagonist tocilizumab may be the key to reduce mortality. International Journal of Antimicrobial Agents, 55(5), 105954. https://doi.org/10.1016/j. ijantimicag.2020.105954

Zhou, G., \& Zhao, Q. (2020). Perspectives on therapeutic neutralizing antibodies against the novel coronavirus SARS-CoV-2. International Journal of Biological Sciences, 16(10), 1718-1723. https://doi.org/10.7150/ijbs.45123 